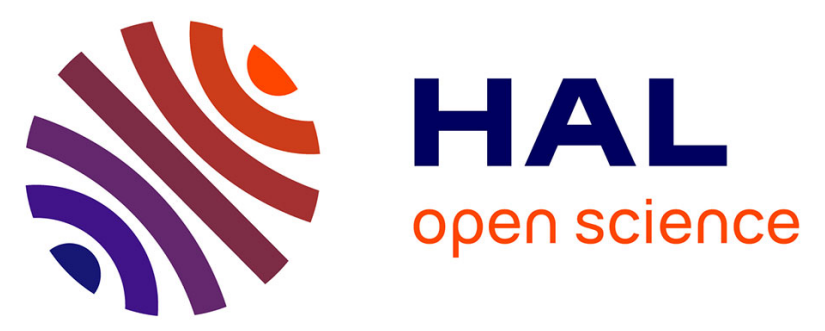

\title{
Enantioseparation on Riboflavin Derivatives Chemically Bonded to Silica Gel as Chiral Stationary Phases for HPLC
}

Daisuke Kumano, Soichiro Iwahana, Hiroki Iida, Chengshuo Shen, Jeanne Crassous, Eiji Yashima

\section{To cite this version:}

Daisuke Kumano, Soichiro Iwahana, Hiroki Iida, Chengshuo Shen, Jeanne Crassous, et al.. Enantioseparation on Riboflavin Derivatives Chemically Bonded to Silica Gel as Chiral Stationary Phases for HPLC. Chirality, 2015, 27 (8), pp.507-517. 10.1002/chir.22452 . hal-01154208

HAL Id: hal-01154208

https://hal-univ-rennes1.archives-ouvertes.fr/hal-01154208

Submitted on 3 Nov 2015

HAL is a multi-disciplinary open access archive for the deposit and dissemination of scientific research documents, whether they are published or not. The documents may come from teaching and research institutions in France or abroad, or from public or private research centers.
L'archive ouverte pluridisciplinaire HAL, est destinée au dépôt et à la diffusion de documents scientifiques de niveau recherche, publiés ou non, émanant des établissements d'enseignement et de recherche français ou étrangers, des laboratoires publics ou privés. 


\title{
Enantioseparation on Riboflavin Derivatives Chemically-Bonded to Silica Gel as Chiral Stationary Phases for HPLC
}

\author{
Daisuke Kumano, ${ }^{1}$ Soichiro Iwahana, ${ }^{1}$ Hiroki lida, ${ }^{1 \dagger}$ Chengshuo Shen,,${ }^{1,2}$ Jeanne Crassous,${ }^{2}$ and \\ Eiji Yashima ${ }^{1 *}$
}

\author{
${ }^{1}$ Department of Molecular Design and Engineering, Graduate School of Engineering, Nagoya University, Chikusa-ku, Nagoya 464- \\ 8603, Japan \\ ${ }^{2}$ Sciences Chimiques de Rennes, UMR 6226, Campus de Beaulieu, CNRS-Université de Rennes 1, 35042 Rennes Cedex, France \\ tPresent address: Department of Chemistry, Interdisciplinary Graduate School of Science and Engineering, Shimane University, \\ 1060 Nishikawatsu, Matsue 690-8504, Japan
}

Correspondence to: Eiji Yashima, Department of Molecular Design and Engineering, Graduate School of Engineering, Nagoya University, Chikusa-ku, Nagoya 4648603, Japan. E-mail: yashima@apchem.nagoya-u.ac.jp

\begin{abstract}
Acetylated and/or 3,5-dimethylphenylcarbamated riboflavins were prepared and the resulting riboflavin derivatives as well as natural riboflavin were regioselectively immobilized on silica gel through chemical bonding at the $5^{\prime}$-O- or 3-N-position of the riboflavin to develop novel chiral stationary phases (CSPs) for enantioseparation by high-performance liquid chromatography (HPLC). The chiral recognition abilities of the obtained CSPS were significantly dependent on the structures of the riboflavin derivatives, the position of the chemical bonding on the silica gel, and the structures of the racemic compounds. The CSPs bonded at the 5'-O-position on the silica

gel tended to well separate helicene derivatives, while the CSPs bonded at the 3-N-position composed of acetylated and 3,5dimethylphenylcarbamated riboflavins showed a better resolving ability toward helicene derivatives and bulky aromatic racemic

alcohols, respectively, and some of them were completely separated into the enantiomers. The observed difference in the chiral recognition abilities of these riboflavin-based CSPs is discussed based on the difference in their structures, including the substituents of riboflavin and the positions immobilized on the silica gel.
\end{abstract}

Keywords: riboflavin, chiral recognition, chiral stationary phase, helicene

\section{Introduction}

The separation of enantiomers by high-performance liquid chromatography (HPLC) has been recognized as one of the most useful techniques not only for obtaining both enantiomers on a large scale, but also for the precise determination of the enantiomeric excess of the chiral analytes including chiral drugs. ${ }^{1-}$ ${ }^{4}$ The development of a chiral stationary phase (CSP) showing an efficient chiral recognition for a variety of enantiomers is of key importance for this purpose. Therefore, a number of chiral stationary phases (CSPs) for HPLC has been prepared in the past few decades, and more than 100 CSPs have been commercialized, ${ }^{5}$ which mostly consist of synthetic or polysaccharide-derived helical polymers ${ }^{6-11}$ or are derived from optically-active synthetic or naturally-occurring small molecules including amino acids, crown ethers, and cinchona alkaloids. ${ }^{12-15}$

Riboflavin (vitamin $B_{2}$ ) is an important unit of cofactors of biologically-active flavoenzymes ${ }^{16}$ and provides a variety of functions, such as catalytic and redox activities and a photoluminescent ability. Hence the readily-available natural riboflavin consisting of a diverse functional heterocyclic isoalloxazine ring together with an optically-active ribityl group and its derivatives have been considered as a promising class of novel asymmetric organocatalysts ${ }^{17,18}$ and chiral materials for sensing ${ }^{19}$ and separating enantiomers, but successful examples for the use as a CSP are still rare except for one precedent by Gil-Av et al.;20 they found that natural riboflavin had a high chiral recognition ability toward carbohelicenes ([7] to [14]helicene) when coated on silica gel as a CSP for HPLC using a mixture of $n$-hexane and
$\mathrm{CH}_{2} \mathrm{Cl}_{2}$ as the eluent. Recently, Papadimitrakopoulos and coworkers have also demonstrated that the flavin mononucleotide (FMN), a phosphorylated analog of riboflavin, self-assembled and wrapped around single-walled carbon nanotubes (SWCNTs) in a chirality and handedness selective way and enriched the lefthanded helical SWCNTs. ${ }^{21}$ These results suggest that riboflavin and its derivatives may have the potential as promising CSPs for separation of polyaromatic racemic compounds through $\pi-\pi$ interactions including charge-transfer complexation between the analytes and isoalloxazine ring of the riboflavin ${ }^{20}$ when they are chemically-bonded to silica gel. ${ }^{22-25}$ Riboflavin has reactive hydroxy and amino groups, and modification with various substituents and further chemical bonding to silica gel are possible.

In this study, we prepared five new riboflavin-based CSPs composed of natural riboflavin and its acetylated and/or 3,5dimethylphenylcarbamated derivatives by regioselective 
immobilization at the 5'-O- or 3-N-position of the riboflavin on silica gel (Fig. 1), and their chiral recognition abilities were evaluated. Among the possible derivatization methods of the hydroxy groups of the ribityl unit, we employed 3,5-dimethylphenylcarbamoylation because the CSPs composed of the tris(3,5dimethylphenylcarbamate)s of cellulose and amylose developed by Okamoto et al. exhibit an excellent chiral resolving ability for a wide range of racemic compounds and are recognized as the most frequently used CSPs. ${ }^{4-7,9-11}$
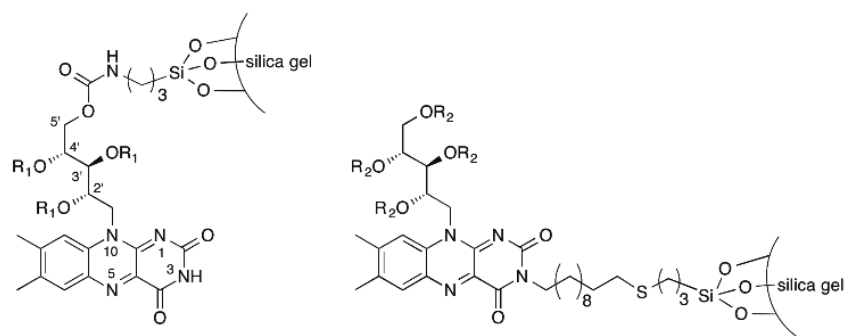

$\mathrm{R}_{1}=\mathrm{H} \quad \operatorname{CSP}_{\mathrm{A}}$ (ca. $80 \%$ regioselectivity)

$\mathrm{R}_{2}=\mathrm{H} \quad \mathrm{CSP}_{\mathrm{C}}$

$\mathrm{R}_{1}=\mathrm{COCH}_{3} \quad \operatorname{CSP}_{\mathrm{B}}$

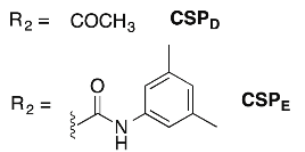

Fig. 1. Structures of riboflavin-based chiral stationary phases.

\section{Materials and Methods}

\section{Instruments}

The NMR spectra were measured using a Varian VXR-500S spectrometer (Varian, Palo Alto, CA) operating at $500 \mathrm{MHz}$ for ${ }^{1} \mathrm{H}$ and $125 \mathrm{MHz}$ for ${ }^{13} \mathrm{C}$ using tetramethylsilane (TMS) for $\mathrm{CDCl}_{3}$ as the internal standard. The IR spectra were recorded on a JASCO FT/IR-680 spectrometer (JASCO, Tokyo, Japan). The chromatographic separations of enantiomers were performed using a JASCO PU-2080 Plus liquid chromatograph equipped with Multi UV-Vis (JASCO MD-2010 Plus or MD-2018 Plus) and CD detectors (JASCO CD-1595 or CD-2095 Plus) at ca. $25^{\circ} \mathrm{C}$. A solution of racemate was injected into the chromatographic system using a Rheodyne Model $7725 \mathrm{i}$ injector (20 $\mu \mathrm{L}$ loop). The thermogravimetric (TG) analyses were conducted on a SEIKO EXSTAR6000 TG/DTA 6200 (Seiko Instruments Inc., Chiba, Japan) under a heating rate of $10^{\circ} \mathrm{C} / \mathrm{min}$ in a nitrogen flow of 200 $\mathrm{mL} / \mathrm{min}$.

\section{Chemicals and Reagents}

Anhydrous dimethylformamide (DMF), dimethyl sulfoxide (DMSO), chloroform $\left(\mathrm{CHCl}_{3}\right)$, pyridine, and tetrahydrofuran (THF) (water content $<0.005 \%)$, methanol $(\mathrm{MeOH})$, ethanol $(\mathrm{EtOH})$, acetone, $n$-hexane, $N, N$-dimethyl-4-aminopyridine (DMAP), and 1,8-diazabicyclo [5.4.0]-7-undecene (DBU) were purchased from Wako (Osaka, Japan). Riboflavin (RF), 3-(triethoxysilyl)propyl isocyanate, 11-bromo-1-undecene (5), p-toluenesulfonic acid monohydrate, 2,2'-azobis(isobutyronitrile) (AIBN), and 3,5dimethylphenyl isocyanate were purchased from Tokyo Kasei (TCI, Tokyo, Japan). Hydrogen chloride in diethyl ether (1.0 M) was obtained from Aldrich (Milwaukee, WI). Triethylamine and acetic anhydride were obtained from Kishida (Osaka, Japan). Tetraacetylriboflavin $\quad$ (TARF), ${ }^{26} \quad$ (3-mercaptopropyl)triethoxy silanized silica gel (M-silica, $8.3 \mathrm{wt} \%$ ) with a mean particle size of $7 \mu \mathrm{m}$ and a mean pore diameter of $12 \mathrm{~nm},{ }^{27}$ and 5'-O-trityl riboflavin (TrRF) ${ }^{28}$ were prepared according to the previously reported methods. The solvents used in the chromatographic experiments were of HPLC grade. The racemates were commercially available or were prepared by the usual or reported methods. ${ }^{29-31}$ The synthesis of new [6]helicene derivatives (2628) will be reported elsewhere. Porous spherical silica gel (Daiso gel SP-120-7P, N-silica) with a mean particle size of $7 \mu \mathrm{m}$ and a mean pore diameter of $12 \mathrm{~nm}$ was kindly supplied from Daicel (Tokyo, Japan).

\section{Synthesis}

Synthesis of Compound 1. The synthesis of 1 was carried out according to Scheme 1. To a solution of $\mathbf{R F}(1.08 \mathrm{~g}, 2.87 \mathrm{mmol})$ in anhydrous DMF $(400 \mathrm{~mL})$ were added 3-(triethoxysilyl)propyl isocyanate $(710 \mu \mathrm{L}, 2.88 \mathrm{mmol})$ and triethylamine $(400 \mu \mathrm{L}, 2.87$ $\mathrm{mmol})$ under nitrogen. The reaction mixture was stirred at $80^{\circ} \mathrm{C}$ for $24 \mathrm{~h}$, and then the solvent was evaporated to give $1(1.71 \mathrm{~g})$. The residue was used for the next reaction without further purification (see below for immobilization of the compound 1 on silica gel, Scheme 8). Among four possible carbamate derivatives, the main-product was found to be the 5 '-carbamated riboflavin (Scheme 1) produced by the reaction at the primary hydroxy group at the 5'-O-position and its regioselectivity was about $80 \%$ estimated from its ${ }^{1} \mathrm{H}$ NMR spectrum (see Spectrum $\mathrm{S} 1$ in the Supporting Information (SI)).
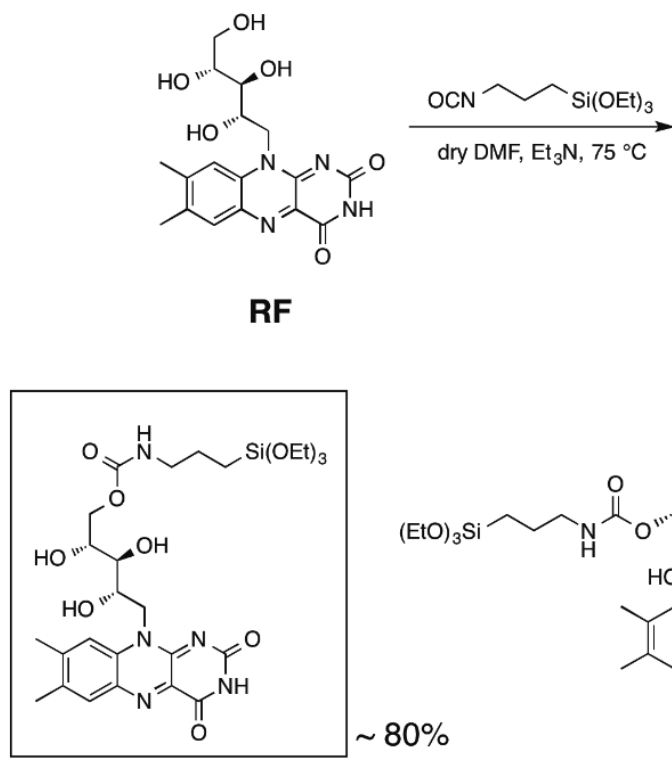<smiles>CCO[SiH2]CCCNC(=O)O[C@H](CO)[C@@H](O)[C@H](O)Cn1c2nc(=O)[nH]c(=O)c-2nc2cc(C)c(C)cc21</smiles><smiles>CCOCCCNC(=O)O[C@H](CO)[C@@H](O)CO</smiles>
$80 \%$<smiles>CCOCCCNC(=O)O[C@H](Cn1c2nc(=O)[nH]c(=O)c-2nc2cc(C)c(C)cc21)[C@@H](O)CO</smiles>

1

Scheme 1. Synthesis of 1 . 
Synthesis of Compound 2. The synthesis of $\mathbf{2}$ was carried out according to Scheme 2. To a solution of $\operatorname{TrRF}(1.10 \mathrm{~g}, 2.78 \mathrm{mmol})$, which had been prepared according to the reported method, ${ }^{28}$ and DMAP (261 mg, $2.09 \mathrm{mmol}$ ) in $\mathrm{CHCl}_{3}(93 \mathrm{~mL}$ ) were added anhydrous pyridine $(13 \mathrm{~mL})$ and acetic anhydride $(71 \mathrm{~mL})$ under nitrogen. After the reaction mixture was stirred at room temperature for $24 \mathrm{~h}$, to this was further added acetic anhydride $(20 \mathrm{~mL})$ and anhydrous pyridine $(3.8 \mathrm{~mL})$. After stirring at room temperature for $24 \mathrm{~h}$, the solvents were evaporated. The residue was dissolved in EtOAc $(80 \mathrm{~mL})$ and the solution was washed with brine $(50 \mathrm{~mL} \times 3)$ and then dried over anhydrous $\mathrm{MgSO}_{4}$. After filtration, the solvent was evaporated to dryness. The residue was purified by column chromatography $\left(\mathrm{SiO}_{2}, \mathrm{EtOAc}-n\right.$-hexane $=$ $0: 10$ to $5: 5,9: 1(\mathrm{v} / \mathrm{v}))$ and then subjected to SEC fractionation to give 2 as an orange solid ( $3.2 \mathrm{~g}, 88 \%$ yield).<smiles>Cc1cc2nc3c(=O)[nH]c(=O)nc-3n(C[C@H](O)[C@H](O)[C@H](O)C[O-])c2cc1C</smiles>

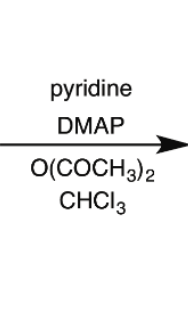<smiles>[CH]OCC(OC(C)=O)C(OC(C)=O)C(OC(C)=O)n1c2nc(=O)[nH]c(=O)c-2nc2cc(C)c(C)cc21</smiles>

Scheme 2. Synthesis of 2.

Spectroscopic data of 2: ${ }^{1} \mathrm{H} \mathrm{NMR}\left(500 \mathrm{MHz}, \mathrm{CDCl}_{3}, 25^{\circ} \mathrm{C}\right): \delta 8.34$ (s, CONH, 1H), $8.04(\mathrm{~s}, \mathrm{ArH}, 1 \mathrm{H}), 7.56(\mathrm{~s}, \mathrm{ArH}, 1 \mathrm{H}), 7.42-7.38(\mathrm{~m}$, OCArH, 9H), 7.24-7.13 (m, OCArH, 6H), 5.69-5.59 (m, NCH $\mathrm{NH}_{2}$, $\left.\mathrm{NCH}_{2} \mathrm{CHCH}, 2 \mathrm{H}\right), 5.38-5.34\left(\mathrm{~m}, \mathrm{NCH}_{2} \mathrm{CHCHCH}, 1 \mathrm{H}\right), 3.46-3.16$ (m, $\left.\mathrm{OCOCH}_{2}, 2 \mathrm{H}\right), 2.53$ (s, $\left.\mathrm{ArCH}_{3}, 3 \mathrm{H}\right), 2.44$ (s, $\left.\mathrm{ArCH}_{3}, 3 \mathrm{H}\right), 2.37$ (s, $\mathrm{CH}_{3} \mathrm{COO}, 3 \mathrm{H}$ ), 1.90 (s, $\mathrm{CH}_{3} \mathrm{COO}, 3 \mathrm{H}$ ), 1.68 (s, $\mathrm{CH}_{3} \mathrm{COO}, 3 \mathrm{H}$ ).

Synthesis of Compound 3. The compound 3 was prepared according to Scheme 3. The compound $2(2.19 \mathrm{~g}, 2.94 \mathrm{mmol})$ was dissolved in anhydrous $\mathrm{CHCl}_{3}(34 \mathrm{~mL})$ under nitrogen and the solution was stirred at $0{ }^{\circ} \mathrm{C}$ for $30 \mathrm{~min}$. To this was added diethyl ether containing $\mathrm{HCl}(1.0 \mathrm{M})(11 \mathrm{~mL})$ and the reaction mixture was stirred at $0{ }^{\circ} \mathrm{C}$ for $45 \mathrm{~min}$ so as to remove the trityl group. The solution was then neutralized with aqueous $\mathrm{NaHCO}_{3}(50 \mathrm{~mL})$ and extracted with $\mathrm{CHCl}_{3}(20 \mathrm{~mL})$. The organic layer was washed with water $(50 \mathrm{~mL})$ and brine $(50 \mathrm{~mL})$, and then dried over anhydrous $\mathrm{MgSO}_{4}$. After filtration, the solvent was evaporated to dryness. The residue was purified by column chromatography $\left(\mathrm{SiO}_{2}\right.$, $\mathrm{MeOH}-\mathrm{CHCl}_{3}=0: 10$ to $\left.1: 9(\mathrm{v} / \mathrm{v})\right)$ to give 3 as a yellow solid $(1.11$ g, $75 \%$ yield).<smiles>CCO[C@@H](C(CO)OC(C)=O)[C@H](Cn1c2nc(=O)[nH]c(=O)c-2nc2cc(C)c(C)cc21)OC(C)=O</smiles>

2
3

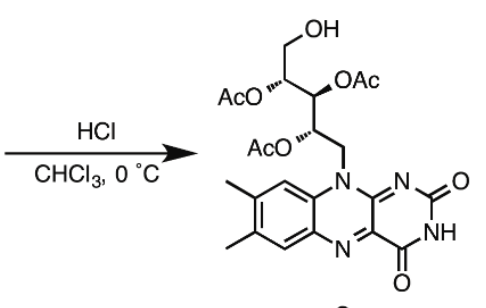

Scheme 3. Synthesis of 3.

Spectroscopic data of 3: ${ }^{1} \mathrm{H}$ NMR $\left(500 \mathrm{MHz}, \mathrm{CDCl}_{3}, \mathrm{rt}\right.$ ): $\delta 8.08$ (s, $\mathrm{ArH}, 1 \mathrm{H}), 7.76(\mathrm{~s}, \mathrm{ArH}, 1 \mathrm{H}), 5.73-5.65\left(\mathrm{~m}, \mathrm{NCH}_{2} \mathrm{CH}, 1 \mathrm{H}\right), 5.30-$ $5.24\left(\mathrm{~m}, \mathrm{NCH}_{2} \mathrm{CHCH}, 1 \mathrm{H}\right), 4.30-4.25\left(\mathrm{~m}, \mathrm{OHCH}_{2}, 2 \mathrm{H}\right), 3.64(\mathrm{~s}$, $\mathrm{NCH}_{2} \mathrm{CHCHCH}, 1 \mathrm{H}$ ), 2.58 (s, $\left.\mathrm{ArCH}_{3}, 3 \mathrm{H}\right), 2.47$ (s, $\left.\mathrm{ArCH}_{3}, 3 \mathrm{H}\right)$, $2.12\left(\mathrm{~s}, \mathrm{CH}_{3} \mathrm{COO}, 3 \mathrm{H}\right), 2.09$ (s, $\left.\mathrm{CH}_{3} \mathrm{COO}, 3 \mathrm{H}\right), 1.97$ (s, $\mathrm{CH}_{3} \mathrm{COO}$, $3 \mathrm{H})$.

Synthesis of Compound 4. The synthesis of $\mathbf{4}$ was carried out according to Scheme 4. To a solution of $3(502 \mathrm{mg}, 1.00 \mathrm{mmol})$ in anhydrous DMF $(10 \mathrm{~mL})$ were added 3-(triethoxysilyl)propyl isocyanate $(737 \mu \mathrm{L}, 2.98 \mathrm{mmol})$ and triethylamine $(413 \mu \mathrm{L}, 2.98$ $\mathrm{mmol}$ ) under nitrogen. After the reaction mixture was stirred at $75^{\circ} \mathrm{C}$ for $24 \mathrm{~h}$, the solvents were evaporated. The residue was washed with $n$-hexane $(200 \mathrm{~mL})$ and purified by column chromatography $\left(\mathrm{SiO}_{2}\right.$, EtOAc- $n$-hexane $=0: 10$ to $\left.5: 5,9: 1(\mathrm{v} / \mathrm{v})\right)$ and then subjected to SEC fractionation to give $\mathbf{4}$ as an orange solid (280 $\mathrm{mg}, 38 \%$ yield).<smiles>COC(Cn1c2nc(=O)[nH]c(=O)c-2nc2cc(C)c(C)cc21)C(OC)C(O)CO</smiles>

3

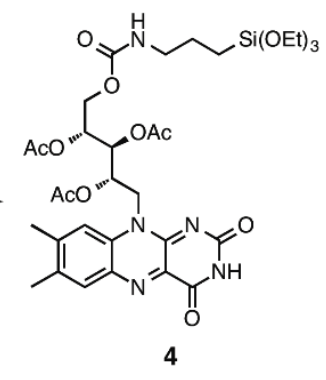

Scheme 4. Synthesis of 4.

Spectroscopic data of 4: $\mathrm{Mp}: 206.7^{\circ} \mathrm{C}$ (dec); IR $\left(\mathrm{KBr}, \mathrm{cm}^{-1}\right)$ : 3173 , $3019,2810,1742,1663,1579,1542,1226,104 ;{ }^{1} \mathrm{H}$ NMR $(500$ $\left.\mathrm{MHz}, \mathrm{CDCl}_{3}, 25^{\circ} \mathrm{C}\right): \delta 8.50(\mathrm{~s}, \mathrm{CONH}, 1 \mathrm{H}), 8.03(\mathrm{~s}, \mathrm{ArH}, 1 \mathrm{H}), 7.57$ (s, ArH, $1 \mathrm{H}), 5.72-5.62\left(\mathrm{~m}, \mathrm{NCH}_{2} \mathrm{CH}, 1 \mathrm{H}\right), 5.48-5.38(\mathrm{~m}$, $\left.\mathrm{NCH}_{2} \mathrm{CHCH}, \mathrm{NCH}_{2} \mathrm{CHCHCH}, 2 \mathrm{H}\right), 4.46-4.21\left(\mathrm{~m}, \mathrm{OCOCH}_{2}, 2 \mathrm{H}\right)$, 3.86-3.78 (q, $J=7.1 \mathrm{~Hz}, \mathrm{SiOCH}_{2}, 6 \mathrm{H}$ ), 3.35-3.25 (t, $J=6.8 \mathrm{~Hz}$, OCONHCH (s, $\left.\mathrm{CH}_{3} \mathrm{COO}, 3 \mathrm{H}\right), 2.22$ (s, $\left.\mathrm{CH}_{3} \mathrm{COO}, 3 \mathrm{H}\right), 2.08\left(\mathrm{~s}, \mathrm{CH}_{3} \mathrm{COO}, 3 \mathrm{H}\right)$, 1.74-1.71 (m, OCONHCH$\left.{ }_{2} \mathrm{CH}_{2}, 2 \mathrm{H}\right), 1.31-1.20$ (t, $\mathrm{SiOCH}_{2} \mathrm{CH}_{3}$, $9 \mathrm{H}), 0.70-0.65\left(\mathrm{~m}, \mathrm{SiCH}_{2}, 2 \mathrm{H}\right) ;{ }^{13} \mathrm{C}$ NMR $\left(125 \mathrm{MHz}, \mathrm{CDCl}_{3}, 25^{\circ} \mathrm{C}\right)$ : $170.77,170.44170 .03,169.88,159.42,154.49,150.87,148.28$, $137.16,136.20,134.79,133.14,131.38,115.67,70.63,69.59$, 69.16, 62.03, 58.62, 45.54, 45.18, 25.26, 21.61, 21.19, 20.94, 20.47, 19.60, 18.42, 7.70; HRMS (ESI+): $\mathrm{m} / \mathrm{z}$ calcd for $\mathrm{C}_{33} \mathrm{H}_{47} \mathrm{~N}_{5} \mathrm{O}_{13} \mathrm{Si}\left(\mathrm{M}+\mathrm{Na}^{+}\right)$772.2837; found 772.2803.

Synthesis of Compound 6. The compound 6 was prepared according to Scheme 5 . To a solution of $5(4.4 \mathrm{~mL}, 20 \mathrm{mmol})$ and TARF $(2.20 \mathrm{~g}, 4.04 \mathrm{mmol})^{26}$ in anhydrous DMF $(190 \mathrm{~mL})$ was added DBU $(1.2 \mathrm{~mL}, 8.0 \mathrm{mmol})$ under nitrogen. After the reaction mixture was stirred at $50^{\circ} \mathrm{C}$ for $20 \mathrm{~h}$, the solvent was evaporated, and the residue was washed with $n$-hexane $(100 \mathrm{~mL} \times 2)$. The residue was then dissolved in $\mathrm{CHCl}_{3}(250 \mathrm{~mL})$ and the solution was washed with water $(300 \mathrm{~mL} \times 4)$, and then dried over anhydrous $\mathrm{MgSO}_{4}$. After filtration, the solvent was evaporated to dryness, and the residue was purified by column chromatography $\left(\mathrm{SiO}_{2}, \mathrm{CHCl}_{3}-n\right.$-hexane $=1: 1$ to $1: 0(\mathrm{v} / \mathrm{v})$ then $\mathrm{MeOH} / \mathrm{CHCl}_{3}=$ $0 / 100$ to $5 / 95(\mathrm{v} / \mathrm{v}))$ and $\mathrm{MeOH}-\mathrm{CHCl}_{3}=0: 10$ to $\left.1: 9(\mathrm{v} / \mathrm{v})\right)$ to give 6 as an orange solid $(2.1 \mathrm{~g}, 73 \%$ yield). 


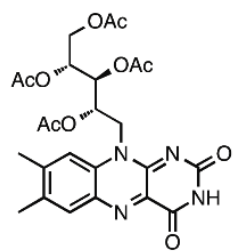

TARF

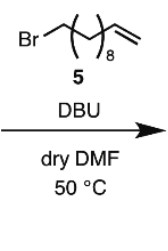

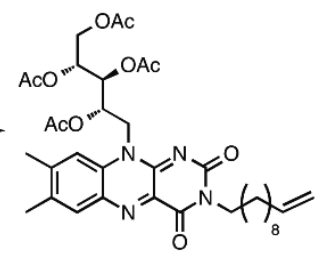

6
Scheme 5. Synthesis of 6 .

Spectroscopic data of 6: Mp: $67.5-69.3^{\circ} \mathrm{C}$; IR $\left(\mathrm{KBr}, \mathrm{cm}^{-1}\right)$ : 2927 , 2855, 1751, 1663, 1588, 1551, 1221, 1050; ${ }^{1} \mathrm{H}$ NMR $(500 \mathrm{MHz}$, $\left.\mathrm{CDCl}_{3}, 25{ }^{\circ} \mathrm{C}\right): \delta 8.03(\mathrm{~s}, \mathrm{ArH}, 1 \mathrm{H}), 7.53(\mathrm{~s}, \mathrm{ArH}, 1 \mathrm{H}), 5.86-5.76$ (ddt, $\left.J=17.1,10.3,6.7 \mathrm{~Hz}, \mathrm{CH}_{2} \mathrm{CH}=\mathrm{CH}_{2}, 1 \mathrm{H}\right), 5.72-5.62(\mathrm{~m}$, $\left.\mathrm{NCH}_{2} \mathrm{CH}, 1 \mathrm{H}\right), 5.50-5.44\left(\mathrm{~m}, \mathrm{NCH}_{2} \mathrm{CHCH}, 1 \mathrm{H}\right), 5.44-5.37(\mathrm{~m}$, $\left.\mathrm{NCH}_{2} \mathrm{CHCHCH}, 1 \mathrm{H}\right), 5.02-4.95\left(\mathrm{~m}, \mathrm{CH}=\mathrm{CH}_{2} \mathrm{H}_{\mathrm{E}}, 1 \mathrm{H}\right), 4.94-4.89$ (m, $\left.\mathrm{CH}=\mathrm{CH}_{\mathrm{E}} \mathrm{H}_{\mathrm{Z}}, 1 \mathrm{H}\right), 4.47-4.21\left(\mathrm{~m}, \mathrm{OCOCH}_{2}, 2 \mathrm{H}\right), 4.09-4.12$ (t, $\left.J=7.6 \mathrm{~Hz}, \quad \mathrm{NCH}_{2} \mathrm{C}_{8} \mathrm{H}_{16} \mathrm{CH}=\mathrm{CH}_{2}, 2 \mathrm{H}\right), 2.55\left(\mathrm{~s}, \mathrm{ArCH}_{3}, 3 \mathrm{H}\right), 2.44$ (s, $\left.\mathrm{ArCH}_{3}, 3 \mathrm{H}\right), 2.30$ (s, $\left.\mathrm{CH}_{3} \mathrm{COO}, 3 \mathrm{H}\right), 2.22$ (s, $\left.\mathrm{CH}_{3} \mathrm{COO}, 3 \mathrm{H}\right)$, $2.08\left(\mathrm{~s}, \mathrm{CH}_{3} \mathrm{COO}, 3 \mathrm{H}\right), 2.05-2.00\left(\mathrm{~m}, \mathrm{CH}_{2} \mathrm{CH}=\mathrm{CH}_{2}, 2 \mathrm{H}\right), 1.73(\mathrm{~s}$, $\left.\mathrm{CH}_{3} \mathrm{COO}, 3 \mathrm{H}\right), 1.74-1.66\left(\mathrm{~m}, \mathrm{NCH}_{2} \mathrm{C}_{7} \mathrm{H}_{14}, 2 \mathrm{H}\right), 1.40-1.26(\mathrm{~m}$, $\left.\mathrm{NCH}_{2} \mathrm{C}_{7} \mathrm{H}_{14}, 12 \mathrm{H}\right) ;{ }^{13} \mathrm{C} \mathrm{NMR}\left(125 \mathrm{MHz}, \mathrm{CDCl}_{3}, 25^{\circ} \mathrm{C}\right): \delta 170.76$, $170.45,170.02,169.79,159.75,155.14,149.26,147.45,139.43$, $136.54,135.97,134.78,133.08,131.29,115.45,114.20,70.54$, $69.57,69.13,62.03,44.55,42.26,33.96,29.61,29.57,29.49$, 29.26, 29.08, 27.90, 27.14, 21.53, 21.21, 20.95, 20.84, 20.47, 19.56; HRMS (ESI+): $\mathrm{m} / \mathrm{z}$ calcd for $\mathrm{C}_{36} \mathrm{H}_{48} \mathrm{~N}_{4} \mathrm{O}_{10}\left(\mathrm{M}+\mathrm{Na}^{+}\right)$ 719.3268; found 719.3286 .

Synthesis of Compound 7. The synthesis of 7 was carried out according to Scheme 6 . The compound $6(7.97 \mathrm{~g}, 11.4 \mathrm{mmol})$ and p-toluenesulfonic acid monohydrate $(6.61 \mathrm{~g}, 34.7 \mathrm{mmol})$ were dissolved in $\mathrm{EtOH}(820 \mathrm{~mL})$ and the solution was refluxed for 16 $\mathrm{h}$ under nitrogen. The reaction mixture was then cooled to $-20{ }^{\circ} \mathrm{C}$. The precipitated solid was collected by filtration and washed with $\mathrm{EtOH}(60 \mathrm{~mL})$ to give 7 as an orange solid ( $3.94 \mathrm{~g}, 65 \%$ yield).

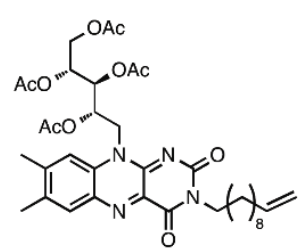

6
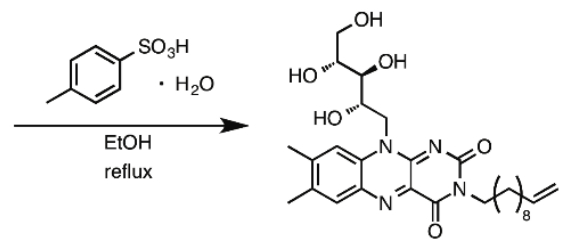

7
Scheme 6. Synthesis of 7.

Spectroscopic data of 7: Mp: $164.0-167.9^{\circ} \mathrm{C}$; IR $\left(\mathrm{KBr}, \mathrm{cm}^{-1}\right): 3400$, 2925, 1546; ${ }^{1} \mathrm{H}$ NMR (500 MHz, DMSO- $\left.d_{6}, 25{ }^{\circ} \mathrm{C}\right)$ : $\delta 7.94$ (s, ArH, $1 \mathrm{H}), 7.93(\mathrm{~s}, \mathrm{ArH}, 1 \mathrm{H}), 5.84-5.72$ (ddt, $J=17.3,10.1,6.9 \mathrm{~Hz}$, $\left.\mathrm{CH}_{2} \mathrm{CH}=\mathrm{CH}_{2}, 1 \mathrm{H}\right), 5.18-5.05(\mathrm{~s}, \mathrm{OH}, 1 \mathrm{H}), 5.02-4.95(\mathrm{~m}, \mathrm{CH}=$ $\left.\mathrm{CH}_{\mathrm{Z}} \mathrm{H}_{\mathrm{E}}, 1 \mathrm{H}\right), 4.94-4.89\left(\mathrm{~m}, \mathrm{CH}=\mathrm{CH}_{\mathrm{E}} \mathrm{H}_{\mathrm{Z}}, 1 \mathrm{H}\right), 4.89-4.80(\mathrm{~m}$, $\left.\mathrm{NCH}_{2} \mathrm{CH}, \mathrm{OH}, 2 \mathrm{H}\right), 4.79-4.77(\mathrm{~m}, \mathrm{OH}, 1 \mathrm{H}), 4.64-4.60(\mathrm{~m}$, $\left.\mathrm{NCH}_{2} \mathrm{CHCH}, 1 \mathrm{H}\right), 4.51-4.49(\mathrm{~m}, \mathrm{OH}, 1 \mathrm{H}), 4.30-4.21(\mathrm{~m}$, $\mathrm{NCH}_{2} \mathrm{CHCHCH}, 1 \mathrm{H}$ ), 3.90-3.83 (t, $J=7.6 \mathrm{~Hz}, \mathrm{NCH}_{2} \mathrm{C}_{8} \mathrm{H}_{16} \mathrm{CH}=$ $\left.\mathrm{CH}_{2}, 2 \mathrm{H}\right), 3.70-3.42\left(\mathrm{~m}, \mathrm{NCH}_{2}, \mathrm{OCOCH}_{2}, 4 \mathrm{H}\right), 2.48$ (s, $\left.\mathrm{ArCH}_{3}, 3 \mathrm{H}\right)$, $2.40\left(\mathrm{~s}, \mathrm{ArCH}_{3}, 3 \mathrm{H}\right), 2.05-1.95\left(\mathrm{~m}, \mathrm{CH}_{2} \mathrm{CH}=\mathrm{CH}_{2}, 2 \mathrm{H}\right), 1.62-1.18$ (m, $\left.\mathrm{NCH}_{2} \mathrm{C}_{7} \mathrm{H}_{14}, 14 \mathrm{H}\right) ;{ }^{13} \mathrm{C}$ NMR $\left(125 \mathrm{MHz}\right.$, DMSO-d $\left.d_{6}, 25^{\circ} \mathrm{C}\right)$ : $159.41,154.65,149.42,146.12$, 138.82, 135.86, 135.79, 134.28, $132.05,130.68,117.41,114.62,114.60,73.55,72.78,68.79$,
$63.41,47.07,33.16,28.90,28.81,28.77,28.50,28.26,27.34$, 26.45, 20.77, 18.76; HRMS (ESI+): $\mathrm{m} / z$ calcd for $\mathrm{C}_{28} \mathrm{H}_{40} \mathrm{~N}_{4} \mathrm{O}_{6}(\mathrm{M}$ $+\mathrm{Na}^{+}$) 551.2846; found 551.2863.

Synthesis of Compound 8. The compound $\mathbf{8}$ was prepared according to Scheme 7 . To a solution of $7(1.17 \mathrm{~g}, 2.22 \mathrm{mmol})$ in anhydrous DMF (100 mL) were added anhydrous pyridine $(60 \mathrm{~mL})$ and 3,5-dimethylphenyl isocyanate $(2.0 \mathrm{~mL}, 14 \mathrm{mmol})$ under nitrogen. The reaction mixture was stirred at $80^{\circ} \mathrm{C}$ for $20 \mathrm{~h}$, and then the solvents were evaporated. The residue was dissolved in $\mathrm{CHCl}_{3}(100 \mathrm{~mL})$ and the solution was washed with water $(150 \mathrm{~mL}$ $x 3$ ), and then dried over $\mathrm{Na}_{2} \mathrm{~S}_{2} \mathrm{O}_{4}$. After filtration, the solvent was evaporated to dryness. The residue was purified by column chromatography $\left(\mathrm{SiO}_{2}, \mathrm{EtOAc}-n\right.$-hexane $=1: 9$ to $\left.4: 6(\mathrm{v} / \mathrm{v})\right)$ and then subjected to SEC fractionation to give $\mathbf{8}$ as a yellow solid (1.3 g, $54 \%$ yield).
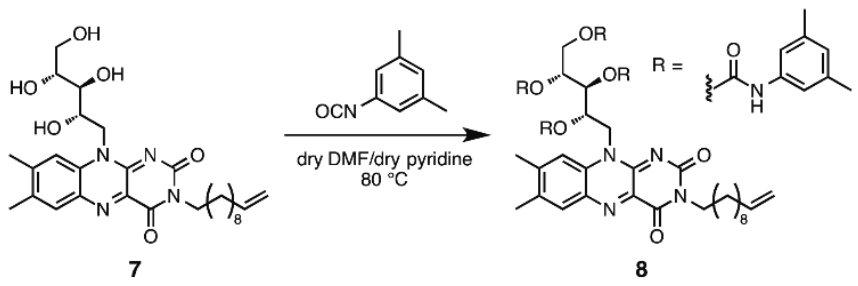

Scheme 7. Synthesis of 8.

Spectroscopic data of 8: Mp: $217.8-219.0{ }^{\circ} \mathrm{C}$; IR $\left(\mathrm{KBr}, \mathrm{cm}^{-1}\right): 3313$, 2924, 1735, 1650, 1585, 1549, 1216; ${ }^{1} \mathrm{H}$ NMR (500 MHz, $\mathrm{CDCl}_{3}$, $\left.25^{\circ} \mathrm{C}\right)$ : $\delta 7.99$ (s, ArH, 1H), 7.63 (s, ArH, 1H), 7.21 (s, OCONHArH, 2H), 7.05 (s, OCONHArH, 2H), 6.85 (s, OCONHArH, 2H), 6.70 (s, OCONHArH, 1H), 6.67 (s, OCONHArH, 1H), 6.65 (s, OCONHArH, $1 \mathrm{H}), 6.60$ (s, OCONHArH, 2H), 6.48 (s, OCONHArH, 2H), 6.005.91 (br, $\mathrm{NCH}_{2} \mathrm{CH}, 1 \mathrm{H}$ ), 5.86-5.77 (ddt, $J=17.1,10.5,6.7 \mathrm{~Hz}$, $\left.\mathrm{CH}_{2} \mathrm{CH}=\mathrm{CH}_{2}, 1 \mathrm{H}\right), 5.61-5.44\left(\mathrm{~m}, \mathrm{NCH}_{2} \mathrm{CHCH}, \mathrm{NCH}_{2} \mathrm{CHCHCH}\right.$, $2 \mathrm{H})$, 5.02-4.95 (m, $\left.\mathrm{CH}=\mathrm{CH}_{\mathrm{Z}} \mathrm{H}_{\mathrm{E}}, 1 \mathrm{H}\right)$, 4.94-4.89 (m, $\mathrm{CH}=\mathrm{CH}_{\mathrm{E}} \mathrm{H}_{\mathrm{Z}}$, $1 \mathrm{H}), 4.76-4.38\left(\mathrm{~m}, \mathrm{OCOCH}_{2}, 2 \mathrm{H}\right), 4.52-4.48\left(\mathrm{br}, \mathrm{NCH}_{2}, 2 \mathrm{H}\right)$, 4.11$3.88\left(\mathrm{~m}, \mathrm{NCH}_{2} \mathrm{C}_{8} \mathrm{H}_{16} \mathrm{CH}=\mathrm{CH}_{2}, 2 \mathrm{H}\right), 2.40\left(\mathrm{~s}, \mathrm{ArCH}_{3}, 3 \mathrm{H}\right), 2.30$ (s, $\mathrm{ArCH}_{3}, 3 \mathrm{H}$ ), 2.29-2.24 (m, OCONHArCH$\left.H_{3}, 12 \mathrm{H}\right), 2.21-2.12$ (m, OCONHArCH$\left.H_{3}, 12 \mathrm{H}\right), 2.04-1.98\left(\mathrm{~m}, \mathrm{CH}_{2} \mathrm{CH}=\mathrm{CH}_{2}, 2 \mathrm{H}\right), 1.69-1.24$ (m, $\left.\mathrm{NCH}_{2} \mathrm{C}_{7} \mathrm{H}_{14}, 14 \mathrm{H}\right) ;{ }^{13} \mathrm{C}$ NMR $\left(125 \mathrm{MHz}, \mathrm{CDCl}_{3}, 25^{\circ} \mathrm{C}\right): 159.91$, $156.48,153.07,152.76,152.72,152.60,148.88,147.68,139.42$, $139.40,138.98,138.82,138.63,138.61,137.87,137.28,136.66$, $136.38,135.87,135.21,132.76,131.66,126.14,125.81,125.28$, $125.06,122.10,117.10,117.01,116.65,116.18,115.52,114.22$, $114.20,107.07,71.71,71.24,63.56,46.07,42.28,33.96,29.65$, 29.60, 29.49, 29.26, 29.08, 27.91, 27.24, 21.56, 21.50, 21.44, 21.35, 19.41; HRMS (ESI+): $m / z$ calcd for $\mathrm{C}_{64} \mathrm{H}_{76} \mathrm{~N}_{8} \mathrm{O}_{10}\left(\mathrm{M}+\mathrm{Na}^{+}\right)$ 1139.5582 ; found 1139.5577 .

Immobilizations of compounds $\mathbf{1 , 4 , 6 , 7}$, and $\mathbf{8}$ on silica gel were carried out according to Scheme 8.

Immobilization of Compounds $\mathbf{1}$ and $\mathbf{4}$ on Silica Gel. A typical experimental procedure is described below. N-Silica (901 mg) was dispersed in a solution of $\mathbf{1}$ just after the preparation (ca. 2.8 $\mathrm{mmol})$ in anhydrous DMSO $(4.0 \mathrm{~mL})$ and pyridine $(1.5 \mathrm{~mL})$ under nitrogen and the mixture was heated at $70{ }^{\circ} \mathrm{C}$. After $25 \mathrm{~h}$, anhydrous DMF $(60 \mathrm{~mL})$ was added to this, and the resulting 


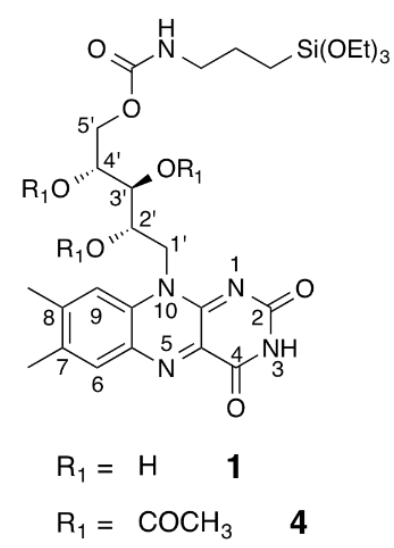

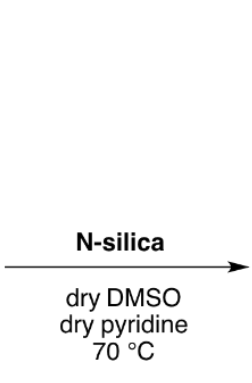

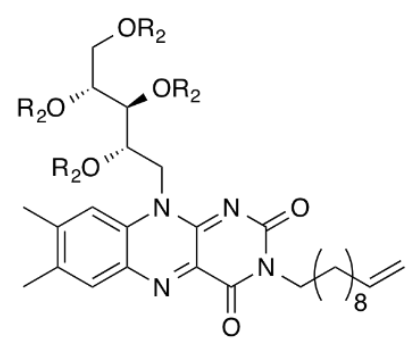<smiles>CC1O[Si]2(C(C)S)OC(C)C(C)O[Si]([N+](=O)[O-])(O1)O2</smiles><smiles>[R][R]=C[Y]([R])=O</smiles>

Scheme 8. Immobilization of $\mathbf{1 , 4 , 6 , 7}$, and 8 on silica gel.

silica gel was collected by filtration, washed with DMF $(20 \mathrm{~mL})$, $\mathrm{MeOH}(60 \mathrm{~mL})$, acetone $(80 \mathrm{~mL})$, and $n$-hexane $(60 \mathrm{~mL})$, and dried in vacuo at $120^{\circ} \mathrm{C}$ overnight, yielding the $\operatorname{CSPA}_{\mathbf{A}}(1.14 \mathrm{~g})$. The content of $\mathbf{1}$ chemically bonded to silica gel was estimated by TG analysis and was $13.4 \mathrm{wt} \%$. In the same way, the compound 4 was chemically bonded to $\mathrm{N}$-silica $\left(\mathbf{C S P}_{\mathbf{B}}\right)$, and its content was estimated to be $13.2 \mathrm{wt} \%$.

Immobilization of Compounds 6, 7, and 8 on Silica Gel. A typical experimental procedure is described below. M-silica (1.00 $\mathrm{g}, 8.3 \mathrm{wt} \%)^{27}$ was dispersed in a solution of 7 (444 mg, 0.638 $\mathrm{mmol})$ in THF (30 mL) under nitrogen, and to this was added AIBN (35.7 $\mathrm{mg}, 0.217 \mathrm{mmol})$. The reaction mixture was refluxed for 24 $\mathrm{h}$, and AIBN (35.5 mg, $0.216 \mathrm{mmol}$ ) was further added. After refluxing for $15 \mathrm{~h}$, the resulting silica gel was collected by filtration, washed with THF $(50 \mathrm{~mL} \times 2)$ and $n$-hexane $(50 \mathrm{~mL})$, and dried in vacuo at $120^{\circ} \mathrm{C}$ overnight. The content of 7 chemically bonded to silica gel was estimated by TG analysis and was $11.8 \mathrm{wt} \%$. In order to improve the amount of 7 bonded to silica gel, the immobilization procedure was repeated two times, giving $\mathrm{CSPc}_{\mathrm{c}}$ $(0.92 \mathrm{~g})$; the content of 7 was $18.4 \mathrm{wt} \%$ thus estimated by TG analysis. In the same way, the compounds 6 and 8 were chemically bonded to M-silica, and their contents were estimated to be $15.9\left(\mathbf{C S P}_{\mathrm{D}}\right)$ and $24.7 \mathrm{wt} \%\left(\mathbf{C S P}_{\mathrm{E}}\right)$, respectively.

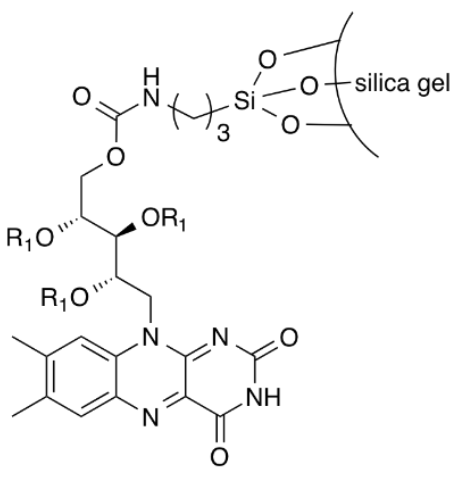

$$
\begin{array}{ll}
\mathrm{R}_{1} & =\mathrm{H} \quad \mathrm{CSP}_{\mathbf{A}} \text { (ca. 80\% regioselectivity) } \\
\mathrm{R}_{1} & =\mathrm{COCH}_{3} \quad \mathbf{C S P}_{\mathbf{B}}
\end{array}
$$

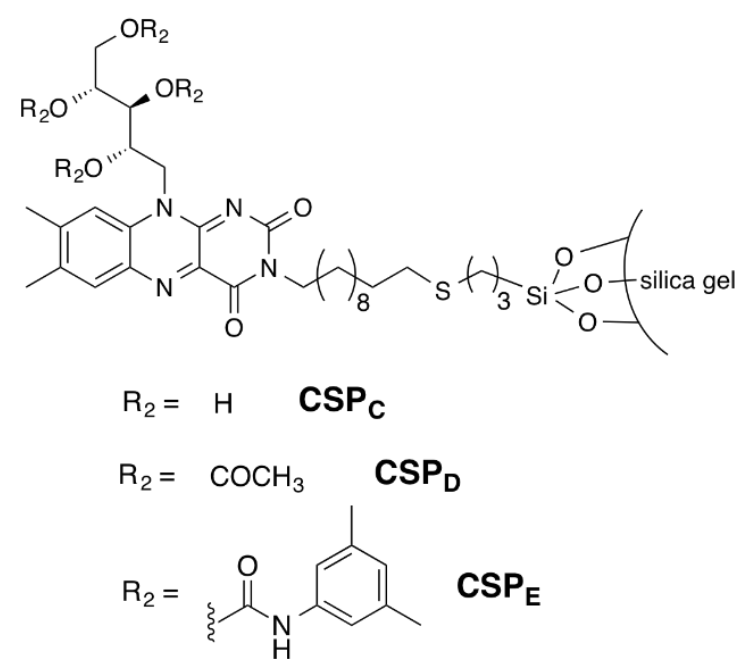

Preparation of Chiral Columns. Each column packing material was packed into a stainless-steel tube $(25 \mathrm{~cm} \times 0.20 \mathrm{~cm}$ (i.d.)) by conventional high-pressure slurry packing technique using a Chemco Slurry-Packing Apparatus Model 124A (Chemco, Osaka, Japan)..$^{29}$ The plate numbers of the columns were $1500-2200$ for benzene with $n$-hexane-2-propanol $(90: 10, \mathrm{v} / \mathrm{v})$ as the eluent at a flow rate of $0.1 \mathrm{~mL} / \mathrm{min}$. The dead time $\left(t_{0}\right)$ was estimated using 1,3,5-tri-tert-butylbenzene as the nonretained compound. ${ }^{32}{ }_{-}$The CSPs are stable and maintained their chiral recognition abilities at least for more than one month.

\section{Results and Discussion}

\section{Synthesis of Riboflavin Derivatives and Immobilization on Silica Gel.}

In order to regioselectively immobilize natural riboflavin and its derivatives $(\mathbf{1}, \mathbf{4}, \mathbf{6}-\mathbf{8})$ on the silica gel $(7 \mu \mathrm{m}$ particle size, $12 \mathrm{~nm}$ pore size) surface via chemical linkages, a 3(triethoxysilyl)propylcarbamate or a 1-undecenyl residue was introduced at the 5'-O- (1 and 4) or 3-N-position (6-8) of the riboflavins, respectively (Scheme 8 ). The precursors were then allowed to react with unmodified silica gel in DMSO in the presence of pyridine or (3-mercaptopropyl)triethoxy silanized silica gel in DMF in the presence of AIBN, ${ }^{27}$ producing the riboflavin-based CSPs regioselectively immobilized on the silica 
gel (Scheme 8 and Fig. 1). Complete regioselective modifications except for 1 (ca. 80\%) were confirmed by the ${ }^{1} \mathrm{H}$ and ${ }^{13} \mathrm{C}$ NMR spectra of the precursors $(4,6-8)$ before the immobilization on silica gel (see Experimental Procedures and Supporting Information). The CSPs were then packed into stainless-steel columns $(25 \mathrm{~cm} \times 0.20 \mathrm{~cm}$ (i.d.)) by the conventional highpressure slurry packing procedure..$^{29}$

\section{Enantioseparation on Riboflavin-Based CSPs.}

Chart 1. Racemates used for resolution on riboflavin-based CSPs (9-31).
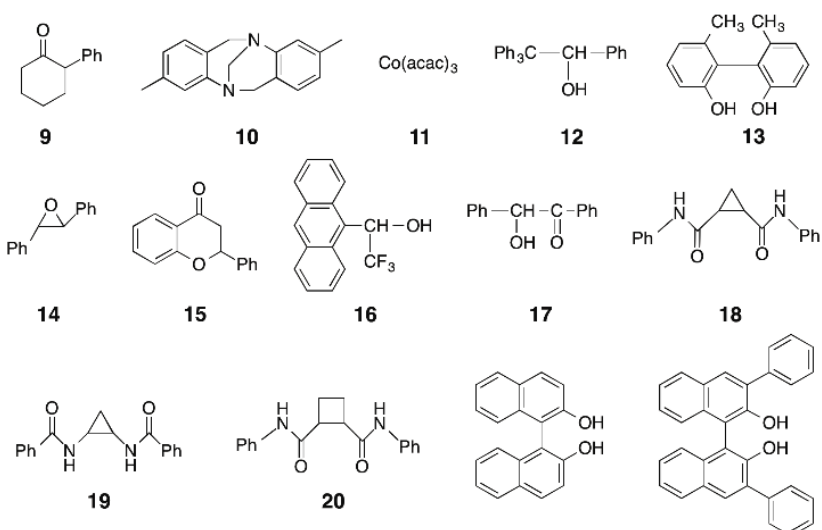

21

22
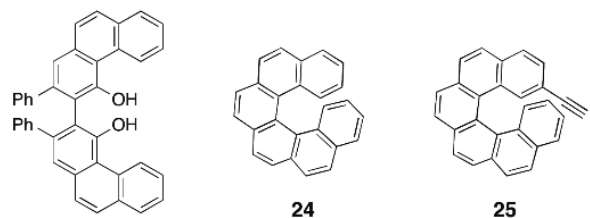

25

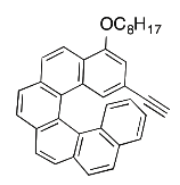

26

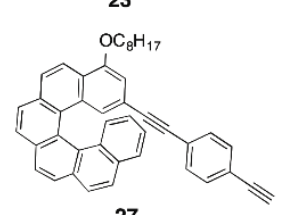

24
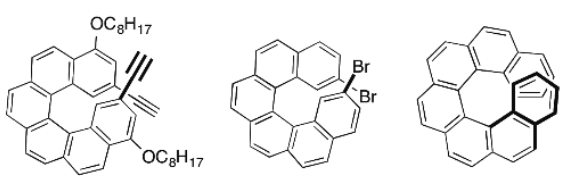

29

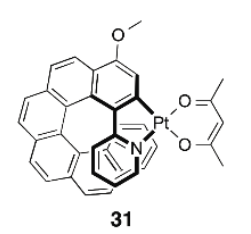

We first performed the chromatographic enantioseparation of ten standard racemic compounds with different structures and functionalities (9-18) (Chart 1) $)^{6,10,24}$ using the five riboflavin-based CSPs with $n$-hexane-2-propanol $(90: 10, \mathrm{v} / \mathrm{v})$ and $n$-hexane$\mathrm{CH}_{2} \mathrm{Cl}_{2}(90: 10, \mathrm{v} / \mathrm{v})$ as the eluent to get an insight into their specific chiral recognition abilities toward such a variety of racemates, and the results are summarized in Table S1 and Table S2, respectively. The chromatographic parameters, the retention factor $k_{1}\left[=\left(t_{1}-t_{0}\right) / t_{0}\right]$, the separation factor $\alpha\left[=\left(t_{2}-t_{0}\right) /\left(t_{1}-t_{0}\right)\right]$, and the resolution factor $R_{S}\left[=2\left(t_{2}-t_{1}\right) /\left(w_{1}+w_{2}\right)\right]$ were used to evaluate the resolution results, where $t_{0}, t_{1}$, and $t_{2}$ are the dead time and the retention times of the first- and second-eluted enantiomers and $w_{1}+w_{2}$ are the peak widths at the base-line, respectively. A chromatogram for the resolution of transcyclopropanedicarboxylic acid dianilide (18) on CSPE using nhexane-2-propanol $(90: 10, \mathrm{v} / \mathrm{v})$ as the eluent is shown in Fig. 2. The peaks were detected by a UV detector and identified by a CD detector. The (-)- and (+)-18 enantiomers eluted at the retention times of $t_{1}$ and $t_{2}$, showed almost base-line separation, and the retention factor $k_{1}$, the separation factor $\alpha$, and the resolution factor $R_{\mathrm{S}}$ were estimated to be $0.78,1.38$ and 1.28 , respectively.

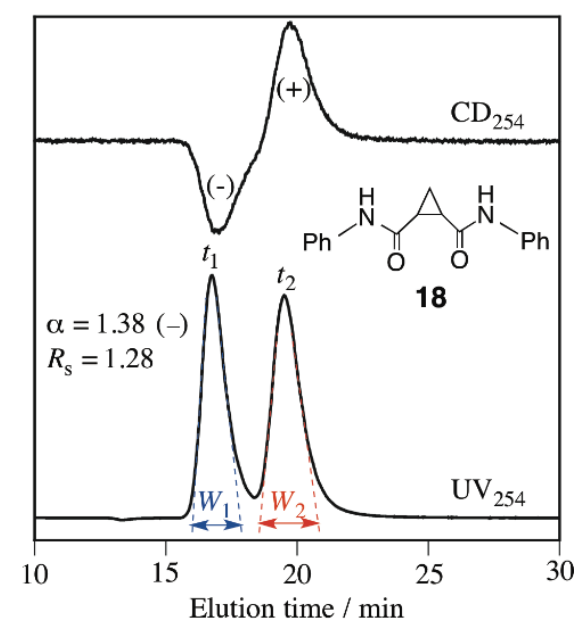

Fig. 2. Chromatograms for the resolution of 18 on $\mathrm{CSP}_{\mathrm{E}}$. Eluent: n-hexane-2-propanol (90:10). Flow rate: $0.1 \mathrm{~mL} / \mathrm{min}$.

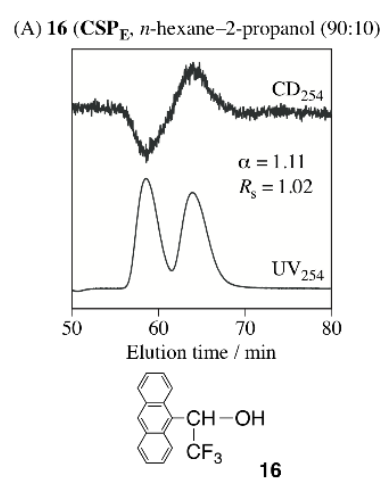

(B) $23\left(\operatorname{CSP}_{\mathbf{C}}, n\right.$-hexane-2-propanol (80:20))

(C) $31\left(\operatorname{CSP}_{\mathrm{D}}, n\right.$-hexane-- $\left.\mathrm{CH}_{2} \mathrm{Cl}_{2}(90: 10)\right)$
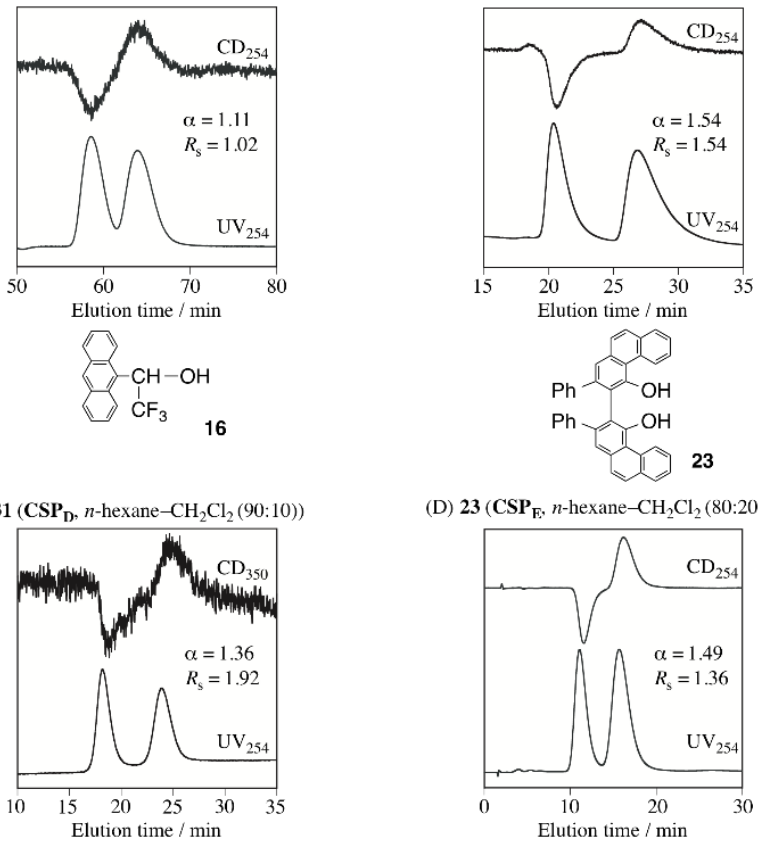

(D) $23\left(\mathrm{CSP}_{\mathrm{E}}, n\right.$-hexane-CH $\left.\mathrm{CH}_{2} \mathrm{Cl}_{2}(80: 20)\right)$
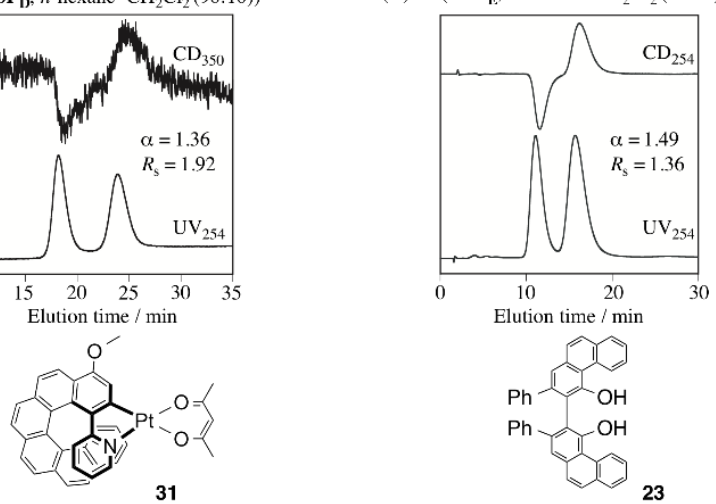

Fig. 3. Chromatograms for the resolution of (A) 16 on $\mathrm{CSP}_{\mathrm{E}}$ (eluent; $n$-hexane-2-propanol (90:10), flow rate; $0.1 \mathrm{~mL} / \mathrm{min}),(\mathrm{B})$ 23 on CSPc (eluent: $n$-hexane-2-propanol $(80: 20)$, flow rate: 0.5 $\mathrm{mL} / \mathrm{min}$ ), (C) 31 on CSP (eluent: $n$-hexane- $\mathrm{CH}_{2} \mathrm{Cl}_{2}$ (90:10), flow rate: $0.5 \mathrm{~mL} / \mathrm{min}$ ), and (D) 23 on $\mathrm{CSP}_{\mathrm{E}}$ (eluent: $n$-hexane- $\mathrm{CH}_{2} \mathrm{Cl}_{2}$ (80:20), flow rate: $0.5 \mathrm{~mL} / \mathrm{min}$ ).

As anticipated from the riboflavin structure in which a chiral, flexible ribityl chain is located away from the achiral heterocyclic isoalloxazine ring, the CSPs separated only two (16 and 18) (Table S1) and three racemates $(\mathbf{1 0}, \mathbf{1 2}$, and 16) (Table S2) with $n$-hexane-2-propanol $(90: 10, \mathrm{v} / \mathrm{v})$ and $n$-hexane- $\mathrm{CH}_{2} \mathrm{Cl}_{2}(90: 10$, $\mathrm{v} / \mathrm{v})$ as the eluents, respectively. The chromatographic resolution results, however, gave useful information regarding the specificity of the CSPs for the racemates and interaction mode between the CSPs and racemates; in the $n$-hexane-2-propanol system, the fully phenylcarbamated CSPE immobilized at the 3-N-position almost completely resolved a bulky aromatic racemic alcohol, 1(9-anthryl)-2,2,2-trifluoroethanol (16) (Fig. 3A) and a 
TABLE 1. Chromatographic resolution results of racemates on riboflavin-based CSPs with $n$-hexane-2-propanol as the eluent ${ }^{\mathrm{a}}$

\begin{tabular}{|c|c|c|c|c|c|c|c|c|c|}
\hline \multirow{2}{*}{ Racemates } & \multicolumn{3}{|c|}{$\mathrm{CSP}_{\mathrm{A}}$} & \multicolumn{3}{|c|}{$\mathrm{CSP}_{\mathrm{B}}$} & \multicolumn{3}{|c|}{$\mathrm{CSP}_{\mathrm{c}}$} \\
\hline & $k_{1}$ & $\alpha$ & $R_{\mathrm{s}}$ & $k_{1}$ & $\alpha$ & $R_{\mathrm{s}}$ & $k_{1}$ & $\alpha$ & $R_{\mathrm{s}}$ \\
\hline 13 & 2.77 & 1 & - & 3.05 & 1 & - & 2.65 & 1 & - \\
\hline 16 & 11.8 & 1 & - & 16.8 & 1 & - & 9.38 & 1 & - \\
\hline 18 & 4.29 & $1.11(-)$ & 0.60 & 4.49 & $1.05(-)$ & 0.48 & 2.54 & ca. $1(-)$ & - \\
\hline 19 & 3.18 & 1 & - & 3.35 & 1 & - & 5.89 & 1 & - \\
\hline 20 & 2.51 & $1.04(-)$ & 0.27 & 1.78 & $1.02(-)$ & 0.22 & 20.4 & 1 & - \\
\hline $21^{\mathrm{b}}$ & 6.73 & ca. $1(+)$ & - & 7.83 & ca.1 (+) & - & 4.89 & ca. $1(-)$ & - \\
\hline $22^{\mathrm{b}}$ & 4.93 & $1.06(+)$ & 0.14 & 4.93 & $1.07(+)$ & 0.17 & 5.23 & ca. $1(-)$ & - \\
\hline $23^{b}$ & 21.3 & ca. $1(-)$ & - & 20.5 & ca. $1(-)$ & - & 16.0 & $1.54(-)$ & 1.54 \\
\hline 24 & 3.00 & ca. $1(-)$ & - & 2.98 & ca. $1(-)$ & - & 1.67 & ca. $1(-)$ & - \\
\hline 30 & 3.49 & $1.07(-)$ & 0.28 & 2.89 & ca. $1(-)$ & - & 2.02 & ca. $1(-)$ & - \\
\hline
\end{tabular}

\begin{tabular}{|c|c|c|c|c|c|c|}
\hline \multirow{2}{*}{ Racemates } & \multicolumn{3}{|c|}{$\mathrm{CSP}_{\mathrm{D}}$} & \multicolumn{3}{|c|}{$\mathrm{CSP}_{\mathrm{E}}$} \\
\hline & $k_{1}$ & $\alpha$ & $R_{\mathrm{s}}$ & $k_{1}$ & $\alpha$ & $R_{\mathrm{s}}$ \\
\hline 13 & 3.00 & ca. $1(-)$ & - & 1.25 & 1 & - \\
\hline 16 & 8.17 & 1 & - & 5.26 & $1.11(-)$ & 1.02 \\
\hline 18 & 2.04 & $1.05(-)$ & 0.23 & 0.78 & $1.38(-)$ & 1.28 \\
\hline 19 & 2.31 & 1 & - & 2.11 & $1.12(-)$ & 0.46 \\
\hline 20 & 1.66 & $1.11(-)$ & 0.30 & 1.54 & 1 & - \\
\hline $21^{\mathrm{b}}$ & 5.30 & ca. $1(-)$ & - & 2.69 & ca. $1(+)$ & - \\
\hline $22^{\mathrm{b}}$ & 6.71 & ca. $1(-)$ & - & 2.31 & $1.25(-)$ & 0.66 \\
\hline $23^{b}$ & 32.2 & $1.27(+)$ & 0.79 & 5.82 & $1.49(-)$ & 1.26 \\
\hline 24 & 1.93 & ca. $1(+)$ & - & 2.12 & ca. $1(-)$ & - \\
\hline 30 & 2.35 & ca. $1(+)$ & - & 2.44 & ca. $1(-)$ & - \\
\hline
\end{tabular}

${ }^{a}$ Conditions: column, $25 \times 0.20$ (i.d.) cm; eluent, $n$-hexane-2-propanol (90:10); flow rate, $0.1 \mathrm{~mL} / \mathrm{min}$; temperature, $25^{\circ} \mathrm{C}$. The signs in parentheses represent the CD detection $(254 \mathrm{~nm}$ ) of the first-eluted enantiomer. 'b Eluent, $n$-hexane-2-propanol (80:20); flow rate, $0.5 \mathrm{~mL} / \mathrm{min}$.

cyclic dianilide 18 (Fig. 2) with high $\alpha$ values $(\alpha=1.11$ and 1.38, respectively) probably through an intermolecular hydrogen bond formation between the polar carbamate residues introduced at the ribityl group of the $\mathrm{CSP}_{\mathrm{E}}$ and the hydroxy or amide residues of the analytes, while the $\mathbf{C S P}_{\mathbf{A}}, \mathbf{C S P}_{\mathbf{B}}$, and $\mathbf{C S P}_{\mathrm{D}}$ only partially resolved 18 (Table S1). A similar trend was observed in the $n$-hexane$\mathrm{CH}_{2} \mathrm{Cl}_{2}$ system for $\mathbf{C S P}_{\mathbf{E}}$ that partially separated the bulky aromatic alcohols 12 and $\mathbf{1 6}$. In contrast to the resolutions in $n$ hexane-2-propanol $(90: 10, \mathbf{v} / \mathbf{v})$, the $\mathbf{C S P}_{\mathbf{A}}$ and $\mathbf{C S P}_{\mathbf{B}}$ immobilized at the 5'-O-position partially resolved the Tröger base (10) in addition to 16 in $n$-hexane- $\mathrm{CH}_{2} \mathrm{Cl}_{2}(90: 10, \mathrm{v} / \mathrm{v})$ (Table S2), indicating that not only hydrogen bonding, but also hydrophobic or $\pi$-stacking interactions may contribute during the chiral recognition process in this eluent system. The CSPc bearing the free ribityl group showed a poor chiral recognition in both eluent systems and could not separate the ten tested racemates. It should be noted that the bulky aromatic racemic alcohols with an acidic hydroxy group $\mathbf{1 3}$ and $\mathbf{1 6}$ strongly interacted with the five CSPs in $n$-hexane- $\mathrm{CH}_{2} \mathrm{Cl}_{2}$, in particular on the CSPc and CSPD, 16 could not elute $\left(k_{1}>100\right)$ under the present conditions.

Based on the above results together with the previously reported intriguing chiral recognition abilities of riboflavin ${ }^{20}$ and $\mathrm{FMN}^{21}$ for the racemic helicenes and SWCNTs, respectively, we employed 13 racemates (19-31) (Chart 1) including the cyclic dibenzamide (19) and dianilide (20), bulky aromatic racemic alcohols (21-23), and helicene derivatives including the [6] and [7]helicenes (24-30) and a metal-containing [8]helicene analog (31) to further evaluate the specific chiral recognition abilities of the riboflavin-based CSPS in $n$-hexane-2-propanol and $n$ hexane- $\mathrm{CH}_{2} \mathrm{Cl}_{2}$ eluent systems; the chromatographic resolution results showing a more or less enantioselectivity $(\alpha>1)$ on either CSP for the racemates are summarized in Table 1 and Table 2, respectively. For comparison, some resolution results in Tables S1 and S2 are also shown.

TABLE 2. Chromatographic resolution results of racemates on riboflavin-based CSPs with $n$-hexane- $\mathrm{CH}_{2} \mathrm{Cl}_{2}$ as the eluent ${ }^{\mathrm{a}}$
As expected, an analogous cyclic dibenzamide (19) and more bulky aromatic alcohols (22 and 23) were partially or almost completely resolved on the phenylcarbamated $\mathbf{C S P}_{\mathrm{E}}$ in $n$-hexane2-propanol (Table 1). The four-membered cyclic dianilide (20) was not resolved on CSPE$_{\mathrm{E}}$, but $\mathbf{2 0}$ as well as the bulky alcohols (22 or 23) were partially resolved on $\mathbf{C S P}_{\mathbf{A}}, \mathbf{C S P}_{\mathbf{B}}$, and $\mathbf{C S P}_{\mathbf{D}}$ and the reversed elution order was observed for 23 on $\mathbf{C S P}_{\mathrm{D}}$. The fact that the relatively less bulky 2,2'-dihydroxy-6,6'-dimethylbiphenyl (13) and 1,1'-bi-2-naphthol (21) were not separated at all on all of the CSPs independent of the eluents (Tables 1 and 2) clearly indicated the important role of the steric or bulky effect, in other words, the molecular size for the efficient separation of aromatic racemic alcohols on the riboflavin-based CSPs. A similar molecular size effect was suggested by Gil-Av during the separation of a series of achiral polyaromatic compounds on silica gel coated with natural riboflavin. ${ }^{20}$ Interestingly, CSPc $_{\mathbf{c}}$ exhibited an exceptionally high chiral recognition ability only for the bulky racemic alcohol $23(\alpha=1.54)$ and completely resolved it (Fig. 3B), although the $\mathbf{C S P}_{\mathbf{c}}$ showed a poor chiral recognition for the other racemates in both eluent systems. In addition, most of the CSPs could not resolve the polycyclic fully aromatic [6] and [7] helicenes (24 and 30) except for CSPA $_{\mathbf{A}}$ bearing mostly free hydroxy groups at the ribityl chain, which partially separated [7]helicene $(\mathbf{3 0})$ into enantiomers.

Interestingly, all of the eight helicene derivatives (24-31) were efficiently recognized by the 5'-O-bonded $\mathbf{C S P}_{\mathbf{A}}$ and $\mathbf{C S P}_{\mathbf{B}}$ except for 29 on $\mathrm{CSP}_{\mathrm{B}}$ in $n$-hexane- $\mathrm{CH}_{2} \mathrm{Cl}_{2}$, showing not complete, but partial separations in the same elution order, while interacting strongly with the CSPs as supported by high $k_{1}$ values (Table 2 ). However, CSPc and CSPE immobilized at the3-N-position could not resolve the helicenes at all, indicating that the interaction of the original isoalloxazine ring of $\mathbf{C S P}_{\mathbf{A}}$ and $\mathbf{C S P}_{\mathbf{B}}$ with the polyaromatic helicenes may be the major driving force for their efficient chiral recognition of the helicenes rather 


\begin{tabular}{|c|c|c|c|c|c|c|c|c|c|}
\hline \multirow{2}{*}{ Racemates } & \multicolumn{3}{|c|}{$\mathrm{CSP}_{\mathrm{A}}$} & \multicolumn{3}{|c|}{$\mathrm{CSP}_{\mathrm{B}}$} & \multicolumn{3}{|c|}{$\mathrm{CSP}_{\mathrm{c}}$} \\
\hline & $k_{1}$ & $\alpha$ & $R_{\mathrm{s}}$ & $k_{1}$ & $\alpha$ & $R_{\mathrm{s}}$ & $k_{1}$ & $\alpha$ & $R_{\mathrm{s}}$ \\
\hline 10 & 10.5 & $1.03(+)$ & 0.23 & 11.2 & $1.03(+)$ & 0.09 & 3.93 & 1 & - \\
\hline 12 & 2.80 & 1 & - & 0.76 & 1 & - & 3.88 & 1 & - \\
\hline 13 & 36.9 & 1 & - & 18.6 & ca. $1(+)$ & - & 40.9 & 1 & - \\
\hline $13^{b}$ & 16.8 & ca. $1(+)$ & - & - & - & - & 13.8 & ca. $1(-)$ & - \\
\hline 16 & 88.3 & $1.17(-)$ & 0.28 & 90.0 & $1.12(-)$ & 0.13 & $>100$ & - & - \\
\hline $16^{b}$ & 65.7 & 1 & - & - & - & - & - & - & - \\
\hline $16^{d}$ & 17.1 & 1 & - & 18.4 & 1 & - & 9.61 & 1 & - \\
\hline 21 & 15.3 & 1 & - & 1.68 & 1 & - & 1.34 & 1 & - \\
\hline $22^{\mathrm{c}}$ & 29.8 & $1.07(+)$ & 0.28 & 19.9 & $1.10(+)$ & 0.26 & 5.82 & ca. $1(+)$ & - \\
\hline $22^{d}$ & 4.07 & $1.08(+)$ & 0.32 & - & - & - & - & - & - \\
\hline $23^{c}$ & $>100$ & - & - & $>100$ & - & - & 31.4 & $1.15(-)$ & 0.54 \\
\hline $23^{d}$ & 20.1 & 1 & - & 16.5 & ca. $1(+)$ & - & 11.6 & $1.28(-)$ & 1.23 \\
\hline $24^{c}$ & 3.37 & $1.05(+)$ & 0.26 & 2.90 & $1.06(+)$ & 0.28 & 0.87 & ca. $1(+)$ & - \\
\hline 25 & 3.66 & $1.04(-)$ & 0.26 & 3.46 & $1.05(-)$ & 0.23 & 2.92 & ca. $1(-)$ & - \\
\hline 26 & 25.0 & $1.08(-)$ & 0.50 & 21.5 & $1.04(-)$ & 0.42 & 33.0 & ca. $1(-)$ & - \\
\hline $26^{\mathrm{b}}$ & 4.43 & $1.07(-)$ & 0.43 & 3.05 & $1.09(-)$ & 0.44 & 0.89 & ca. $1(-)$ & - \\
\hline 27 & 21.0 & $1.07(+)$ & 0.24 & 18.9 & $1.06(+)$ & 0.22 & 52.8 & ca. $1(-)$ & - \\
\hline $27^{\mathrm{b}}$ & 7.71 & $1.03(+)$ & 0.18 & - & - & - & 1.56 & ca. $1(-)$ & - \\
\hline 28 & 30.4 & $1.09(-)$ & 0.52 & 24.1 & $1.05(-)$ & 0.47 & 36.7 & ca. $1(-)$ & - \\
\hline $28^{b}$ & 4.47 & $1.07(-)$ & 0.35 & 2.91 & $1.08(-)$ & 0.35 & 0.81 & ca. $1(-)$ & - \\
\hline 29 & 4.45 & $1.08(-)$ & 0.32 & 3.54 & ca. $1(-)$ & - & 3.39 & ca. $1(-)$ & - \\
\hline 30 & $>100$ & - & - & $>100$ & - & - & 5.09 & 1 & - \\
\hline $30^{c}$ & 5.29 & $1.07(+)$ & 0.34 & 5.30 & $1.07(+)$ & 0.35 & 1.21 & 1 & - \\
\hline $31^{\mathrm{e}}$ & - & - & - & - & - & - & - & - & - \\
\hline $31^{c}$ & 6.66 & $1.16(+)$ & 0.38 & 6.40 & $1.10(+)$ & 0.62 & 7.00 & ca. $1(+)$ & - \\
\hline
\end{tabular}

\begin{tabular}{|c|c|c|c|c|c|c|}
\hline \multirow{2}{*}{ Racemates } & \multicolumn{3}{|c|}{ CSPD } & \multicolumn{3}{|c|}{$\mathrm{CSP}_{\mathrm{E}}$} \\
\hline & $k_{1}$ & $\alpha$ & $R_{\mathrm{s}}$ & $k_{1}$ & $\alpha$ & $R_{\mathrm{s}}$ \\
\hline 10 & 1.66 & 1 & - & 5.45 & 1 & - \\
\hline 12 & 4.55 & 1 & - & 3.05 & $1.07(-)$ & 0.51 \\
\hline 13 & 18.9 & 1 & - & 19.3 & 1 & - \\
\hline 16 & $>100$ & - & - & 71.0 & $1.14(-)$ & 0.38 \\
\hline $16^{d}$ & 9.22 & 1 & - & $16.0^{c}$ & $1.09(-)^{c}$ & $0.44^{\mathrm{c}}$ \\
\hline 21 & 56.8 & ca. $1(-)$ & - & 0.96 & 1 & - \\
\hline $21^{d}$ & 8.81 & ca. $1(-)$ & - & - & - & - \\
\hline $22^{c}$ & 6.58 & ca. $1(-)$ & - & 2.37 & $1.26(-)$ & 0.65 \\
\hline $23^{c}$ & 26.1 & $1.27(+)$ & 0.94 & 5.87 & $1.49(-)$ & 1.36 \\
\hline $23^{d}$ & 14.1 & $1.22(+)$ & 0.62 & - & - & - \\
\hline $24^{c}$ & 0.80 & ca.1 (-) & - & 0.70 & ca. $1(-)$ & - \\
\hline 25 & 2.28 & $1.13(+)$ & 1.13 & 2.04 & ca. $1(-)$ & - \\
\hline 26 & 1.30 & ca. $1(+)$ & - & 16.7 & ca. $1(+)$ & - \\
\hline 27 & 1.86 & $1.17(-)$ & 0.60 & 20.3 & ca. $1(-)$ & - \\
\hline $27^{b}$ & - & - & - & 4.14 & ca. $1(-)$ & - \\
\hline 28 & 1.43 & ca. $1(+)$ & - & 14.2 & ca. $1(-)$ & - \\
\hline 29 & 1.92 & $1.05(+)$ & 0.21 & 2.32 & ca.1 (-) & - \\
\hline 30 & 4.29 & $1.09(-)$ & 0.86 & 3.41 & 1 & - \\
\hline $30^{c}$ & 1.00 & ca. $1(-)$ & - & 0.87 & 1 & - \\
\hline $31^{\mathrm{e}}$ & 10.4 & $1.36(-)$ & 1.92 & - & - & - \\
\hline $31^{\mathrm{c}}$ & 4.86 & $1.27(-)$ & 1.56 & 2.26 & ca. $1(+)$ & - \\
\hline
\end{tabular}

${ }^{\mathrm{a}}$ Conditions: column, $25 \times 0.20$ (i.d.) $\mathrm{cm}$; eluent, $n$-hexane- $\mathrm{CH}_{2} \mathrm{Cl}_{2}(90: 10)$; flow rate, $0.1 \mathrm{~mL} / \mathrm{min}$; temperature, $25{ }^{\circ} \mathrm{C}$. The signs in parentheses represent the $\mathrm{CD}$ detection $(254 \mathrm{~nm}$ ) of the first-eluted enantiomer except for 24, 30, and 31, which were detected at $350 \mathrm{~nm}$. ' Eluent, $n$-hexane- $\mathrm{CH}_{2} \mathrm{Cl}_{2}(90: 10)$ containing 1\% 2-propanol; flow rate, $0.1 \mathrm{~mL} / \mathrm{min}$. ' $E$ Eluent, $n$-hexane- $\mathrm{CH}_{2} \mathrm{Cl}_{2}(80: 20)$; flow rate, $0.5 \mathrm{~mL} / \mathrm{min}$. dEluent, $n$-hexane- $\mathrm{CH}_{2} \mathrm{Cl}_{2}$ (80:20) containing $1 \%$ 2-propanol; flow rate, $0.5 \mathrm{~mL} / \mathrm{min}$. ${ }^{e} F / o w$ rate, $0.5 \mathrm{~mL} / \mathrm{min}$. 
[7]helicene (30) on $\mathbf{C S P}_{\mathbf{A}}$ and $\mathbf{C S P}_{\mathbf{B}}$ was identical to that on the reported riboflavin-coated silica gel $\mathrm{CSP},{ }^{20}$ judging from the Cotton effect sign of the first-eluted enantiomer of $\mathbf{3 0}$ at 350 nm. ${ }^{20,33}$

More interestingly, most of the helicene derivatives, in particular, the [6] helicene derivatives ( 25 and 27 ), [7] helicene (30), and an [8] helicene analog (31) were better resolved on the 3-Nbonded CSP $_{\mathrm{D}}$ composed of the fully-acetylated ribityl residue, and 25 and 31 (Fig. 3C) were completely separated. It is noteworthy that the elution order of the helicene derivatives (24-31) on CSPD was totally reversed without exception when compared to that on $\mathbf{C S P}_{\mathbf{A}}$ and $\mathbf{C S P}_{\mathbf{B}}$ in $n$-hexane- $\mathrm{CH}_{2} \mathrm{Cl}_{2}$ (Table 2). The difference between the acetylated $\mathrm{CSP}_{\mathrm{B}}$ and $\mathrm{CSP}_{\mathrm{D}}$ is the position immobilized on the silica gel (5'-O- and 3-N-positions, respectively). Therefore, the results reveal the critical role of the immobilization positions of the riboflavin-based CSPs during the enantioselectivity of the helicenes as well as their elution order.

Again, CSPE exhibited a good chiral recognition ability for bulky aromatic racemic alcohols (22 and 23$)(\alpha=1.26$ and 1.49, respectively) and completely resolved 23 (Fig. 3D), although CSPE $_{\mathrm{E}}$ showed poor enantioselectivities $(\alpha=$ ca. 1$)$ toward the racemic helicene derivatives. The other CSPs also separated either 22 or 23; the latter bulky alcohol was almost base-line resolved on $\mathrm{CSP}_{\mathrm{D}}$ with the reversed elution order to that on $\mathrm{CSP}_{\mathrm{E}}$. The retention factors of bulky racemic alcohols $(13,16,22$, and 23) as well as helicene derivatives (26-28) significantly decreased when $n$-hexane- $\mathrm{CH}_{2} \mathrm{Cl}_{2}$ (90:10 or $\left.80 / 20\right)$ containing $1 \%$ 2-propanol was used as the eluent (Table 2), while the separation factors slightly decreased or were improved depending on the CSPs.

A comparison of the enantioseparation results on the five riboflavin-based CSPs summarized in Tables 1 and 2 in $n$ hexane-2-propanol and $n$-hexane- $\mathrm{CH}_{2} \mathrm{Cl}_{2}$ eluent systems revealed their specific and relative chiral recognition ability; $\mathbf{C S P}_{\mathbf{A}}$ and CSP $_{\mathbf{B}}$ chemically bonded at the 5'-O-position on the silica gel showed a relatively high chiral recognition toward the helicene derivatives via specific $\pi-\pi$ interactions including charge-transfer complexation between the unmodified isoalloxazine ring and the polyaromatic helicenes and could also partially separate some bulky aromatic alcohols and cyclic amides. On the other hand, $\mathrm{CSP}_{\mathrm{E}}$ bearing the 3,5-dimethylphenylcarbamated ribityl unit bonded at the 3-N-position on silica gel specifically and better resolved the bulky aromatic alcohols and cyclic amides, some of which were completely separated into enantiomers through an intermolecular hydrogen bond formation, although $\mathrm{CSP}_{\mathrm{E}}$ showed a poor chiral recognition ability for the helicene derivatives. The chiral recognition power of these CSPs seems to be complementary. CSPC $_{\mathbf{c}}$ immobilized at the 3-N-position on the silica gel is structurally similar to $\mathbf{C S P}_{\mathbf{A}}$ with respect to the ribityl pendant, but showed a poor chiral recognition ability and specifically resolved only one bulky aromatic alcohol 23. Among the riboflavin-based CSPS, CSP bearing the fully acetylated ribityl residue immobilized at the $3-\mathrm{N}$-position showed quite unique and high chiral recognition abilities for a variety of helicenes and bulky aromatic racemic alcohols with the reversed elution order compared to that on the other CSPs. The enantioselectivity and elution order of the racemates are significantly influenced not only by the position immobilized on the silica gel, but also by the substituents of the ribityl unit.

These findings will contribute to the development of more efficient CSPs composed of novel riboflavins with more suitable substituents and also riboflavin-based polymers. In fact, we recently prepared the first optically-active riboflavin-containing polymer with the fully acetylated riboflavin as the main-chain, which enantioselectively catalyzed the asymmetric oxidation of sulfides whose enantioselectivity was much higher than that catalyzed by the corresponding riboflavin monomer ${ }^{18}$ and also detected the chirality of chiral primary and secondary amine vapors in the solid state. ${ }^{19}$ We believe that such riboflavin-based optically-active polymers will show a better chiral recognition ability than the present riboflavin-based CSPs because such polymers may form a preferred-handed helical structure ${ }^{18,34,35}$ and the research along this line is now in progress in our laboratory.

\section{Acknowledgements}

This work was supported in part by a Grant-in-Aid for Scientific Research (S) (E.Y.) and a Grant-in-Aid for Young Scientists (B) (H.I.) from the Japan Society for the Promotion of Science. C.S expresses his thanks for the Program for Leading Graduate Schools "Integrative Graduate Education and Research in Green Natural Sciences", MEXT, Japan.

\section{Supporting information}

Additional supporting information may be found in the online version of this article at the publisher's website.

\section{LITERATURE CITED}

1. Maier NM, Franco P, Lindner W. Separation of enantiomers: needs, challenges, perspectives. J Chromatogr A 2001;906:3-33. 2. Francotte ER. Enantioselective chromatography as a powerful alternative for the preparation of drug enantiomers. J Chromatogr A 2001;906:379-397.

3. Roussel C, Rio AD, Pierrot-Sanders J, Piras P, Vanthuyne $\mathrm{N}$. Chiral liquid chromatography contribution to the determination of the absolute configuration of enantiomers. J Chromatogr A 2004; $1037: 311-328$

4. Okamoto Y, Ikai T. Chiral HPLC for efficient resolution of enantiomers. Chem Soc Rev 2008;37:2593-2608.

5. Cavazzini A, Pasti L, Massi A, Marchetti N, Dondi F. Recent applications in chiral high performance liquid chromatography: $A$ review. Anal Chimica Acta 2011;706:205-222.

6. Okamoto Y, Yashima E. Polysaccharide derivatives for chromatographic separation of enantiomers. Angew Chem Int Ed 1998:37:1020-1043.

7. Yashima E. Polysaccharide-based chiral stationary phases for high-performance liquid chromatographic enantioseparation. J Chromatogr A 2001;906:105-125.

8. Nakano T. Optically active synthetic polymers as chiral stationary phases in HPLC. J Chromatogr A 2001;906:205-225

9. Yamamoto $\mathrm{C}$, Okamoto Y. Optically active polymers for chiral separation. Bull Chem Soc Jpn 2004;77:227-257.

10. Ikai T, Okamoto Y. Structure control of polysaccharide derivatives for efficient separation of enantiomers by chromatography. Chem Rev 2009;109:6077-6101.

11. Ding P, Chang B, Qing G, Su T. New approach for chiral separation: from polysaccharide-based materials to chiralityresponsive polymers. Sci China Chem 2014;57:1492-1506.

12. Davankov VA. Enantioselective ligand exchange in modern separation techniques. J Chromatogr A 2003;1000:891-915.

13. Hyun $\mathrm{MH}$. Development and application of crown etherbased HPLC chiral stationary phases. Bull Korean Chem Soc 2005;26:1153-1163.

14. Lammerhofer $M$, Lindner $W$. Liquid chromatographic enantiomer separation and chiral recognition by cinchona alkaloid-derived enantioselective separation materials. Adv Chromatogr 2008;46:1-107.

15. D'Acquarica I, Gasparrini F, Misiti D, Pierini M, Villani C. HPLC chiral stationary phases containing macrocyclic antibiotics: practical aspects and recognition mechanism. Adv Chromatogr 2008:46:109-173.

16. Massey, V. The chemical and biological versatility of riboflavin. Biochem Soc Trans 2000;28:283-296.

17. Gonzalo G, Fraaije MW. Recent developments in flavinbased catalysis. ChemCatChem 2013;5:403-415

18. lida H, Iwahana S, Mizoguchi T, Yashima E. Main-chain optically active riboflavin polymer for asymmetric catalysis and its vapochromic behavior. J Am Chem Soc 2012;134:15103-15113. 
19. Iida $\mathrm{H}$, Miki M, Iwahana S, Yashima E. Riboflavin-based fluorogenic sensor for chemo- and enantioselective detection of amine vapors. Chem Eur J 2014;20:4257-4262.

20. Kim YH, Tishbee A, Gil-Av E. Chiral recognition by small biological molecules. Resolution of helicenes on silica gel coated with riboflavin. J Am Chem Soc 1980;102: 5915-5917.

21. Ju SY, Abanulo DC, Badalucco CA, Gascón JA, Papadimitrakopoulos F. Handedness enantioselection of carbon nanotubes using helical assemblies of flavin mononucleotide. $\mathrm{J}$ Am Chem Soc 2012:134:13196-13199.

22. Yashima $\mathrm{E}$, Fukaya H, Okamoto $\mathrm{Y}$. (3,5Dimethylphenyl)carbamates of cellulose and amylose regioselectively bonded to silica gel as chiral stationary phases for high-performance liquid chromatography. J Chromatogr A 1994;677:11-19.

23. Enomoto $\mathrm{N}$, Furukawa $\mathrm{S}$, Ogasawara $\mathrm{Y}$, Akano $\mathrm{H}$, Kawamura Y, Yashima E, Okamoto Y. Preparation of silica gelbonded amylose through enzyme-catalyzed polymerization and chiral recognition ability of its phenylcarbamate derivative in HPLC. Anal Chem 1996;68:2798-2804.

24. Tamura K, Miyabe T, lida H, Yashima E. Separation of enantiomers on diastereomeric right- and left-handed helical poly(phenyl isocyanide)s bearing L-alanine pendants immobilized on silica gel by HPLC. Polym Chem 2011;2:91-98.

25. Miyabe $\mathrm{T}$, lida $\mathrm{H}$, Ohnishi $\mathrm{A}$, Yashima E. Enantioseparation on poly(phenyl isocyanide)s with macromolecular helicity memory as chiral stationary phases for HPLC. Chem Sci 2012;3:863-867. 26. Müller F. Synthesis of 2-substituted riboflavin analogs. Methods Enzymol 1971;18:453-458.

27. Veigl E, Lindner W. Epimeric N-substituted L-proline derivatives as chiral selectors for ligand-exchange chromatography. J Chromatogr A 1994;660:255-268.
28. Takahashi H, Isobe M, Goto T. Chemical synthesis of lampteroflavin as light emitter in the luminous mushroom, Lampteromyces japonicus. Tetrahedron 1991;47:6215-6222.

29. Okamoto Y, Kawashima M, Hatada K. Chromatographic resolution. XI. Controlled chiral recognition of cellulose triphenylcarbamate derivatives supported on silica gel. J Chromatogr A 1986;363:173-186.

30. Anger E, Srebro M, Vanthuyne N, Toupet L, Rigaut S, Roussel C, Autschbach J, Crassous J, Regis R. Rutheniumvinylhelicenes: Remote metal-based enhancement and redox switching of the chiroptical properties of a helicene core. J Am Chem Soc 2012;134;15628-15631.

31. Shen C, Anger E, Srebro M, Vanthuyne N, Deol K, Jefferson T, Muller G, Williams J, Toupet L, Roussel C, Autschbach J, Reau $R$, Crassous J. Straightforward access to mono- and biscycloplatinated helicenes displaying circularly polarized phosphorescence by using crystallization resolution methods. Chem Sci 2014;5;1915-1927.

32. Koller $\mathrm{H}$, Rimböck $\mathrm{KH}$, Mannschreck A. Liquid chromatography on triacetylcellulose. Part VII. High-pressure liquid chromatography on triacetylcellulose. Characterization of a sorbent for the separation of enantiomers. J Chromatogr A 1983;282:89-94.

33. Nakai $\mathrm{Y}$, Mori $\mathrm{T}$, Inoue $\mathrm{Y}$. Theoretical and experimental studies on circular dichroism of carbo[ $n]$ helicenes. J Phys Chem A 2012;116:7372-7385.

34. Nakano T, Okamoto Y. Synthetic helical polymers: conformation and function. Chem Rev 2001;101:4013-4038.

35. Yashima E, Maeda K, lida H, Furusho Y, Nagai K. Helical Polymers: Synthesis, structures, and functions. Chem Rev 2009;109:6102-6211.

\section{Graphical Abstract}

Riboflavin-based Chiral Stationary Phases

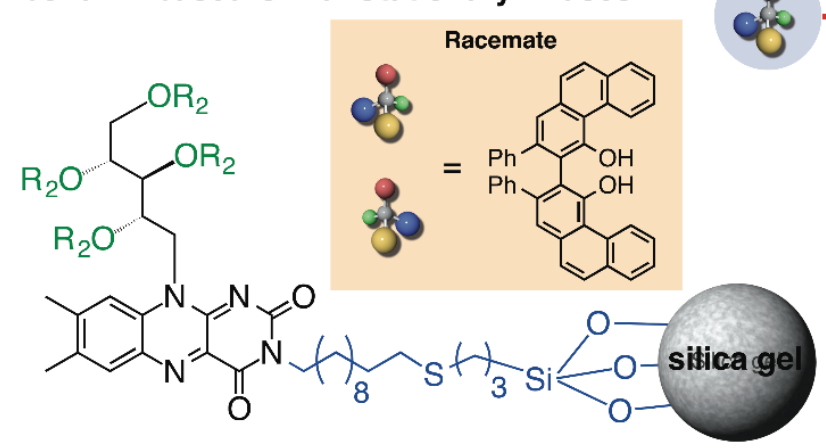

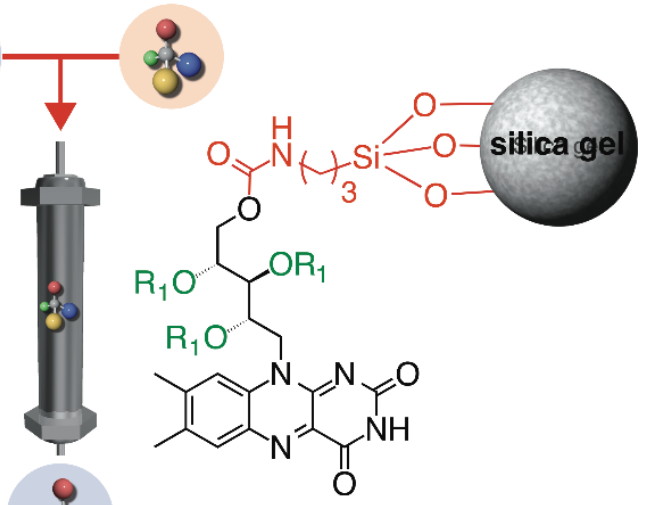

